\title{
Synthesis and Characterization of Polyurethane/POT Dopant and Study Its Electrical Properties
}

\author{
Raed Kadhum Fakher Alfahed ${ }^{1 *}$, K. I. Ajeel ${ }^{1}$ and Salah Shakir ${ }^{2}$ \\ 1. Physics Department, College of Education for Pure Science, University of Basrah, Basrah- 61004, Iraq \\ 2. College of Science, Basrah University, Basrah- 61004, Iraq
}

\begin{abstract}
The Toluene 2, 4-diisocyanate (TDI) (C9 $\mathrm{H} 6 \mathrm{~N}_{2} \mathrm{O}_{2}$ ) and polyethylene glycol (PEG) $\left[\mathrm{H}\left(\mathrm{OCH}_{2} \mathrm{CH}_{2}\right) n \mathrm{OH}\right]$ were used to prepare the poly urethane (PU), and then it is doped by different weight ratios of poly (o-toluidine) as $(20 \%, 30 \%$, and $50 \% \mathrm{w} / \mathrm{w})$. The current-voltage (I-V) characterization of prepared thin films (deposited by spin coating method) showed ohmic behavior and the electrical conductivity increased with respect to increasing the ratio of dopant and all samples reflect a semi-conductor material.
\end{abstract}

Key words: Toluene 2, 4-diisocyanate (TDI), polyethylene glycol (PEG), poly (o-Toluidine) (POT), electrical conductivity.

\section{Introduction}

PU (Poly urethane) has different functional uses like coatings, adhesives and thermoplastic elastomers, etc. due to their high strain restoration and high degree of chemical control over the softening temperatures in addition to have high strength and toughness [1, 2]. Because of these qualities a researchers did not stop the development and introduction of attributes suited to the need. These enhancements were done through the doping processes and fundamental materials used for synthesis of PU, therefor, the dopants used to get better properties are single-walled carbon nanotube (SWNTs) [3, 4] and multi-walled carbon nanotube (MWCNT) $[3,5]$ and other dopants are used as Lewis acid treatment to improve lignin polyurethane and organoclay([chromophore $]^{+}$-saponite) $[6,7]$. One of important approaches to modify the properties of PU is the changing molecular structure by a modification of the basic building blocks [3]. In general the PU has linear structure of two segments : the first is low $\mathrm{Tg}$ soft segment( diol or diamine) and the second is high Tg hard segment (diisocyanate) [8, 9]. In present study,

"Corresponding author: Raed Kadhum Fakher Alfahed, Ph.D., research field: Thin films. the aromatic TDI (Toluene 2, 4-diisocyanate) and PEG (Polyethylene glycol) were used as basic segments to prepare PU which was doped by conductive polymer (Poly(o-toluidine)) because of its properties such as optical and electrical characteristics, inexpensiveness and environmental stability [10] to get material with appropriated electrical properties which were studied and characterized by (FT-IR and $\mathrm{XRD}$ ) techniques.

\section{Experimental}

The 2, 4-diisocyanate (TDI) (C9 $\left.\mathrm{H}_{6 \mathrm{~N}_{2}} \mathrm{O}_{2}\right)$ was purchased from Sigma Aldrich (UK) and used without further purification. Poly (ethylene glycol) (PEG) ( $\mathrm{H}(\mathrm{OCH} 2 \mathrm{CH} 2) \mathrm{nOH})$ with molecular weight $(\mathrm{Mr}$ 16000-24000) was provided from Sigma Aldrich (UK). The poly (O-Toluidine) was prepared according to our previous work [11].

Depending on the previous study of PU which was prepared it by reacting diisocyanate with polytetramethylene glycol as example [5]. In the present study the polyurethane is prepared as a same weight ratios of the TDI and PEG are mixed together for $30 \mathrm{~min}$. to be completely mixed, then brought out to heat the mixture up to $90^{\circ} \mathrm{C}$ for $15 \mathrm{~min}$. By that process, the reaction will be got and the PU polymer was done. 
The method used to doping the PU by POT is done during the preparation of PU. Dissolving the amount of TDI by formic acid and same amount of PEG is dissolved in other tube, then, permitting it to be completely dissolved by using magnetic stirrer and at the same time the amount of POT is dissolved in formic acid where the total weight of TDI and PEG is calculated and different weight ratios of POT $(20 \%$, $30 \%, 50 \%$ ) (With respect to the total weight of TDI and PEG) are added. The continuous stirrer for $1 \mathrm{hr}$ to the final mixture (which is $10 \mathrm{mg}$ per $\mathrm{ml}$ of solvent) is allowed.

The doped PU was deposited on the different substrates by spin coating method which is glass substrate for study the XRD analysis, interdigitated finger for electrical properties. The thicknesses of the prepared films were measured by Ellipsometry instrument to be $(50.74,44.2,44.56$, and $43.24 \mathrm{~nm})$ for pure PU and doped PU respectively.

\section{Results and Discussion}

\subsection{SEM Analysis}

The SEM microphotographs reveal the morphology of the neat PU/POT including composition of film in which $-\mathrm{OH}$ groups of the PEG surface react with the -NOC groups of TDI (Fig. 1). Therefore, the compositions of PU/POT films are well dispersed in matrix of the PU by binding hydrogen which is formed between the segmented chain of the POT and segmented TDI. Moreover, surface of the prepared samples produces hard and rough films without of porous and pin hole.

\subsection{FT-IR Characterizations}

Fig. 2 shows FTIR spectra of PU and doped PU including a disappearance of NCO peak in FTIR spectrum at 2,270-2,250 $\mathrm{cm}^{-1}$ which shows that TDI has a completely reaction to form PU [12-13]. The appearance of $\mathrm{C}=\mathrm{O}$ peak at $1,700 \mathrm{~cm}^{-1}$ indicates that hydrogen bonding is formed between the segmented chain of the POT and the segmented TDI. Formation of the imide group is connected with the disappearance of the characteristic absorption band of the isocyanate group. Moreover, FTIR absorption maximum shows up at $1778 \mathrm{~cm}^{-1}$ and $1718 \mathrm{~cm}^{-1}$ because of imide-carbonyl while at $1,373 \mathrm{~cm}^{-1}$ and at $720 \mathrm{~cm}^{-1}$ due to $\mathrm{C}-\mathrm{N}$ stretching, and imide ring deformation, respectively.

\subsection{XRD Characterizations}

The XRD pattern of pure PU shows that, no sharp peaks, confirming their non-crystalline nature of the PU which is known as amorphous polymer [13]. The XRD pattern shows peaks at $12.18^{\circ}, 14.93^{\circ}, 18.31^{\circ}$, $18.37^{\circ}, 18.87^{\circ}, 20^{\circ}, 21.95^{\circ}$, and $26.2^{\circ}$ as shown in Fig. 3 . The small peaks appeared conformed that, the prepared PU has semi crystalline nature.

The XRD patterns of the doped PU shows peaks at $13.21^{\circ}, 19.24^{\circ}, 23.72^{\circ}, 26.1^{\circ}$ with low intensity and indicated that, POT is successfully incorporated in the PU matrix which is caused to disappear some peaks in addition to some simple displacement in location of peaks as shown in Fig. 4.

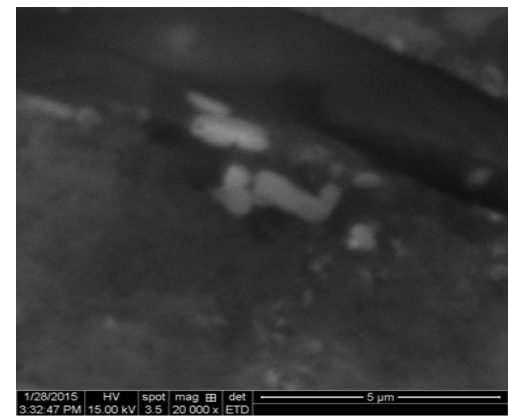

(a)

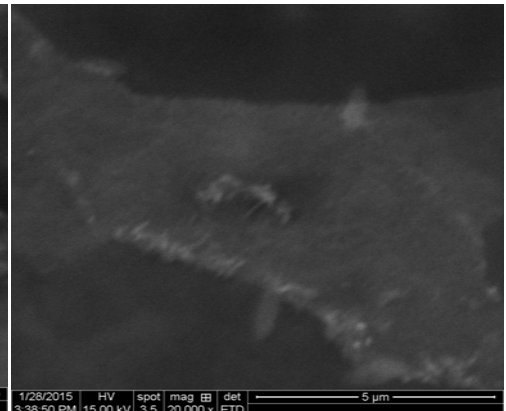

(b)

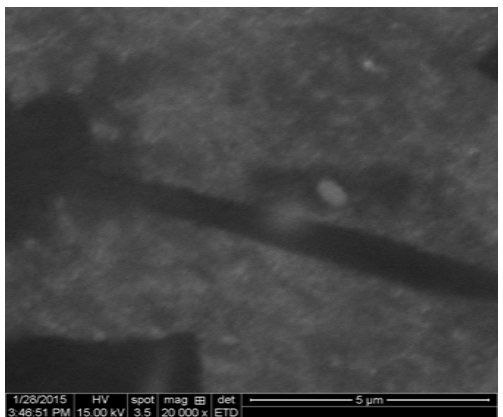

(c)

Fig. 1 SEM image of PU-doped by (a) 20\% POT, (b) 30\%POT and (c) $50 \%$ POT. 


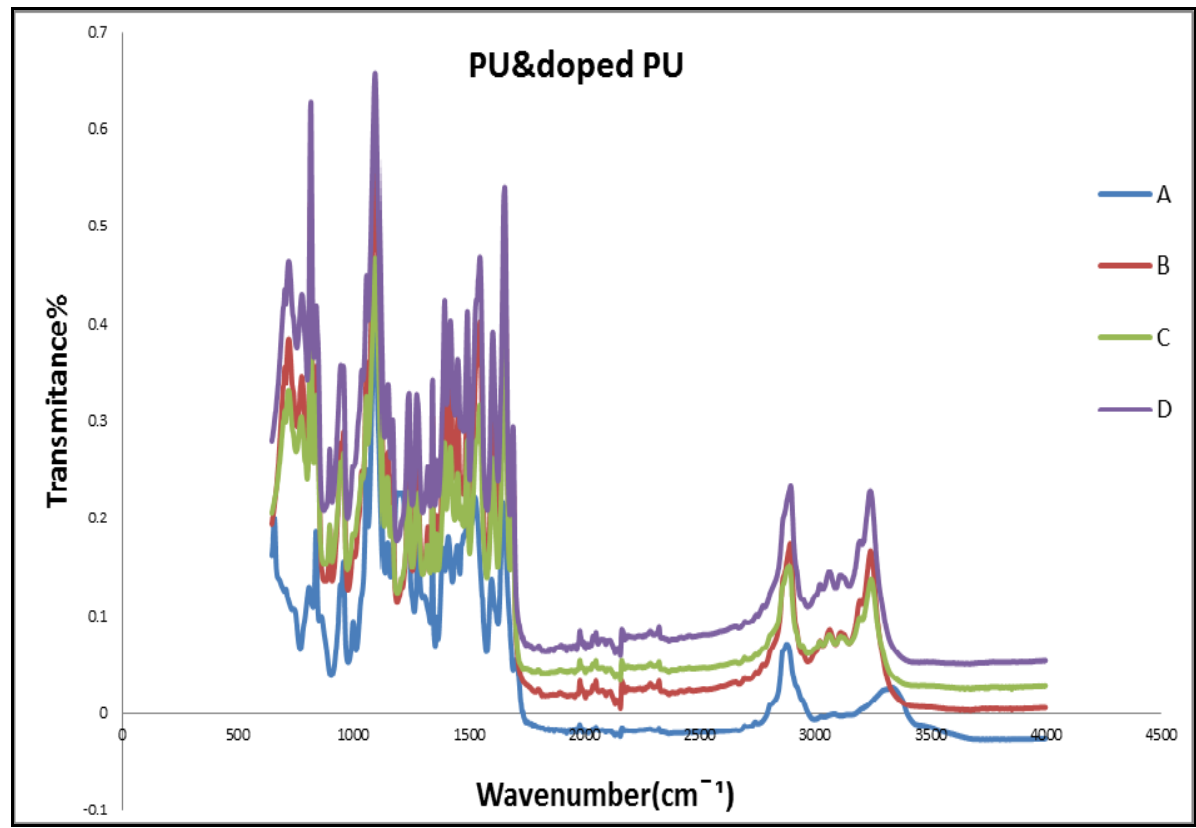

Fig. 2 FT-IR absorption spectra of PU and doped PU: (A) pure PU, (B)PU-20\% POT, (C)PU-30\% POT, (D) PU-50\% POT.

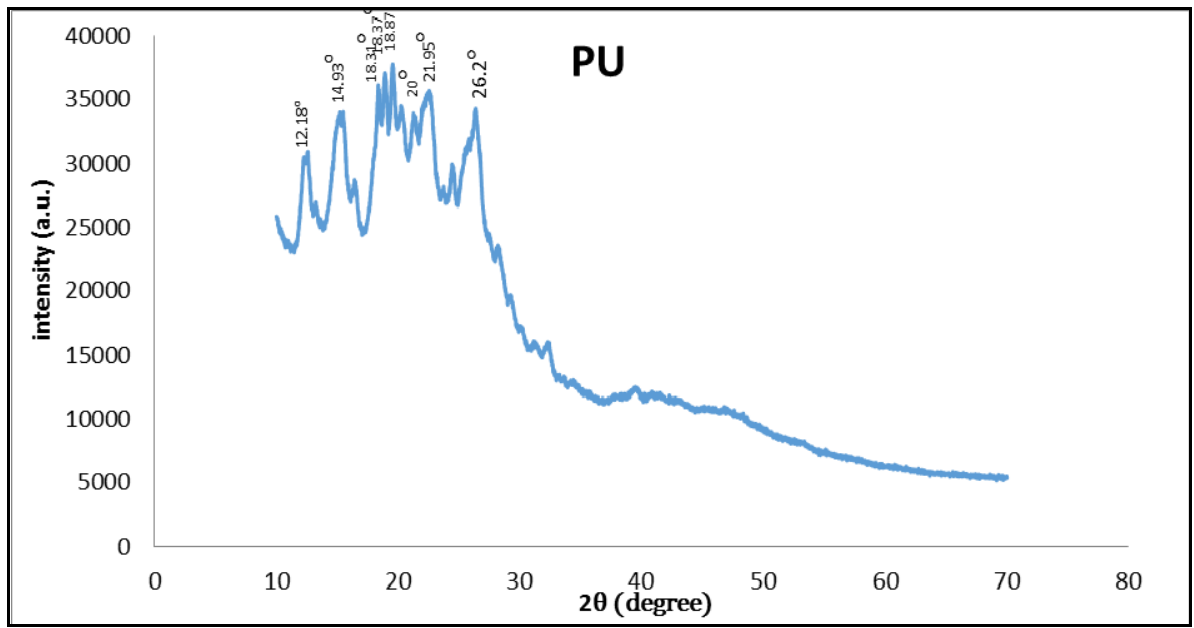

Fig. 3 XRD scattering pattern of polyurethane (PU).

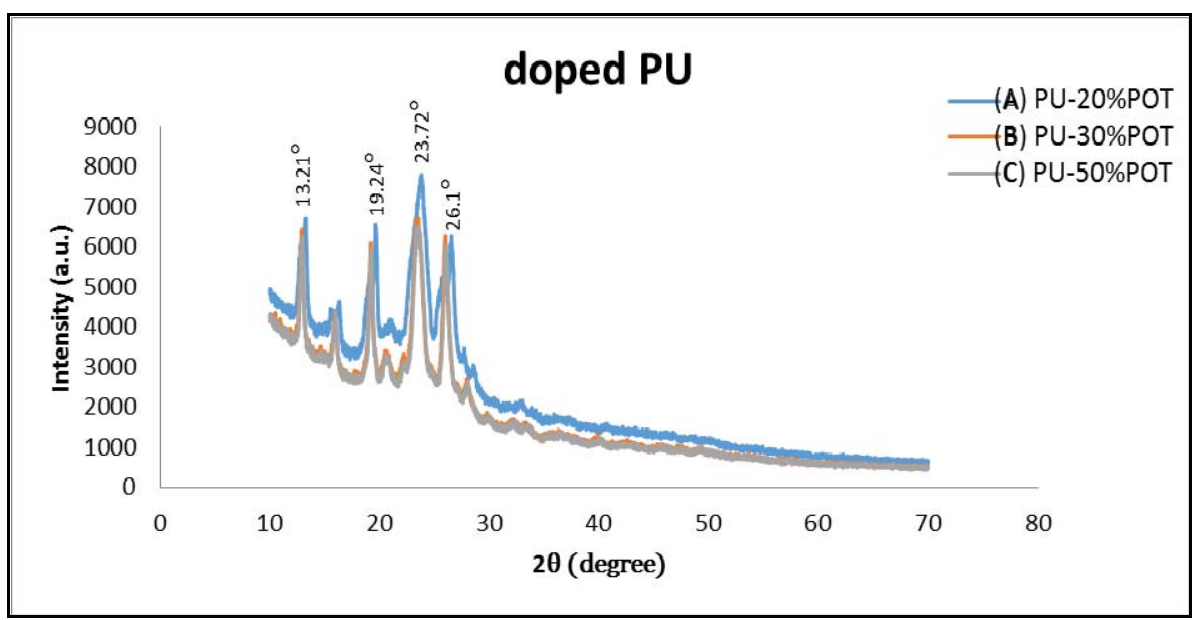

Fig. 4 XRD scattering pattern of doped polyurethane (PU). 


\subsection{Electrical Properties}

The two probe method is used to study electrical properties of prepared polymers and the circuit used in this method including Keithley electrometer instrument (Model 65174), Digital hot plate (IKA RET basic), and computer for display and save the data. Surface conductivity of the prepared samples is measured by using interdigitated electrodes according to the following relationship [14-17].

$$
\sigma_{s}=[\mathrm{I} / \mathrm{V}][\mathrm{L} / \mathrm{Wt} l]
$$

where, $\mathrm{L}$ is the space between electrodes $(100 \mu \mathrm{m}), \mathrm{W}$ is the distance fingers $(10 \mathrm{~mm}), l$ is the number of the fingers is to be (10) and $t$ is the thickness of the film.
The conductivity of the PU (which is considered as insulator polymer) around $9 * 10 \mathrm{E}-11(\mathrm{~S} / \mathrm{cm})[5]$. The conductivity of the dopant (poly (o-toluidine)) is calculated at different temperature started from $1.70 \mathrm{E}-04(\mathrm{~S} / \mathrm{cm})$ at $308 \mathrm{~K}$ to $2.39 \mathrm{E}-04(\mathrm{~S} / \mathrm{cm})$ at $387 \mathrm{~K}$ [11] which is reacted with the PU by forming hydrogen bond between the POT segmented and TDI segmented .The I-V characteristic of the prepared samples with different thickness are shown in Fig. 5 which is displayed ohmic behavior [18, 19].

Surface conductivity of the samples are calculated according to Eq. (1), which is tabulated in the Table 1 which is indicate that, the conductivity increased with
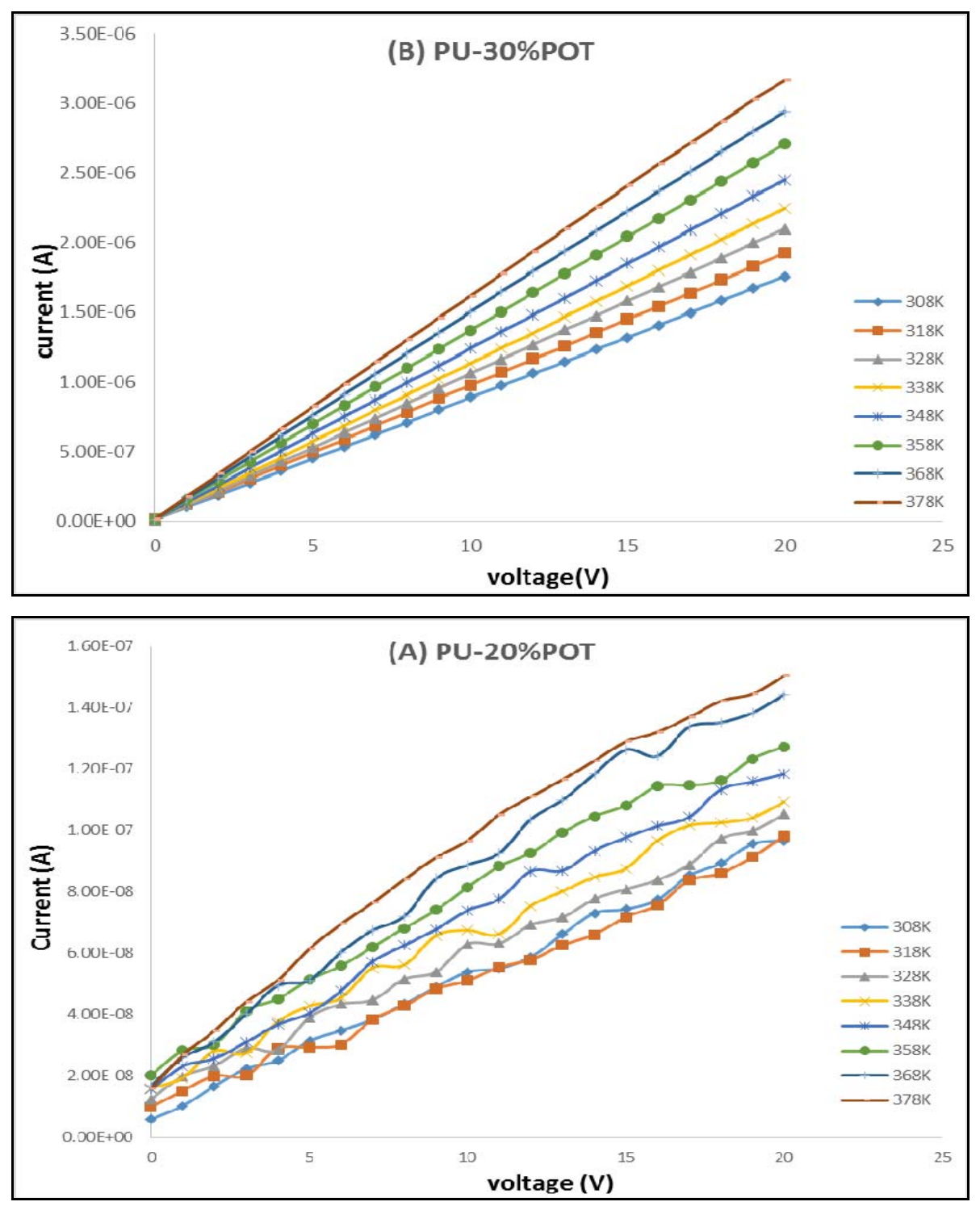


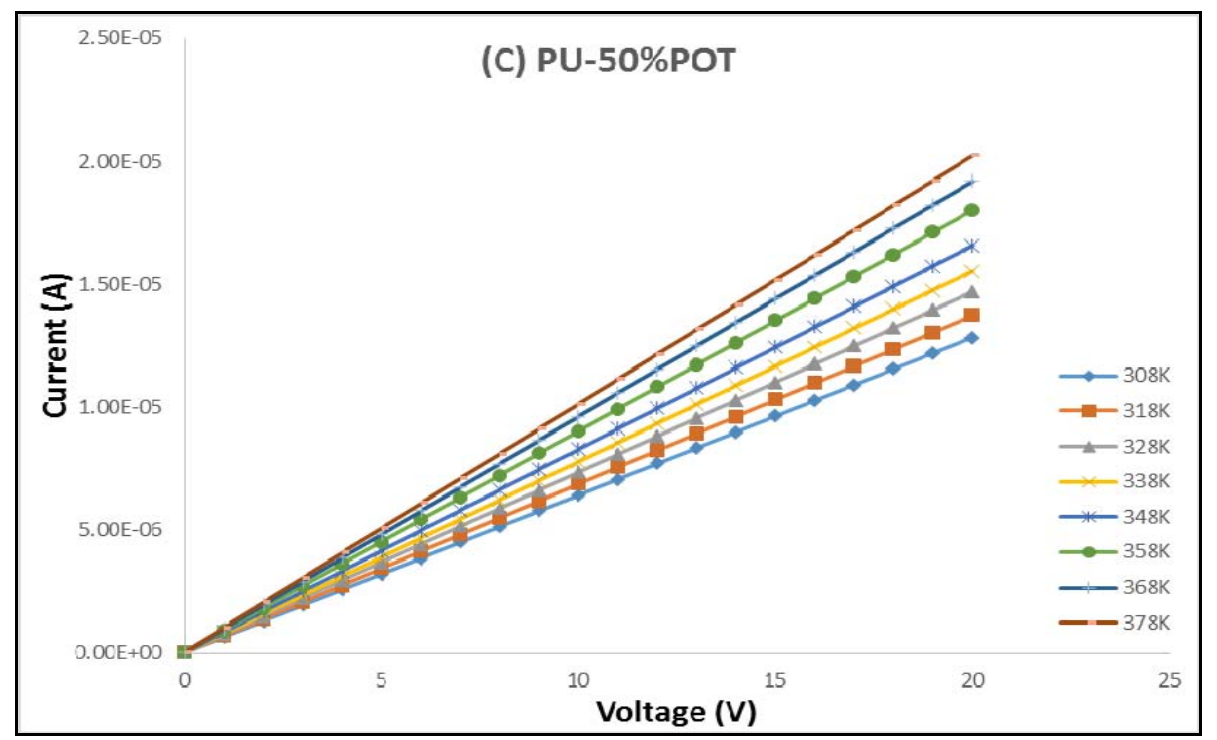

Fig. 5 The Current-Voltage characterization of doped PU by different weight of POT.

Table 1 The electrical conductivity for doped PU at different temperatures.

\begin{tabular}{llll}
\hline $\mathrm{T}(\mathrm{K})$ & $\sigma_{\mathrm{s}}(\mathrm{S} / \mathrm{cm})$ & $\sigma_{\mathrm{s}}(\mathrm{S} / \mathrm{cm})$ & $\sigma_{\mathrm{s}}(\mathrm{S} / \mathrm{cm})$ \\
$20 \%$ doped & $30 \%$ doped & $50 \%$ doped \\
\hline 308 & $9.389 \mathrm{E}-07$ & $1.962 \mathrm{E}-05$ & $1.48 \mathrm{E}-4$ \\
318 & $1.016 \mathrm{E}-06$ & $2.135 \mathrm{E}-05$ & $1.59 \mathrm{E}-4$ \\
328 & $1.026 \mathrm{E}-06$ & $2.357 \mathrm{E}-05$ & $1.696 \mathrm{E}-4$ \\
338 & $1.116 \mathrm{E}-06$ & $2.489 \mathrm{E}-05$ & $1.792 \mathrm{E}-4$ \\
348 & $1.199 \mathrm{E}-06$ & $2.723 \mathrm{E}-05$ & $1.916 \mathrm{E}-4$ \\
358 & $1.254 \mathrm{E}-06$ & $3.009 \mathrm{E}-05$ & $2.076 \mathrm{E}-4$ \\
368 & $1.423 \mathrm{E}-06$ & $3.261 \mathrm{E}-05$ & $2.211 \mathrm{E}-4$ \\
378 & $1.561 \mathrm{E}-06$ & $3.519 \mathrm{E}-05$ & $2.336 \mathrm{E}-4$ \\
\hline
\end{tabular}

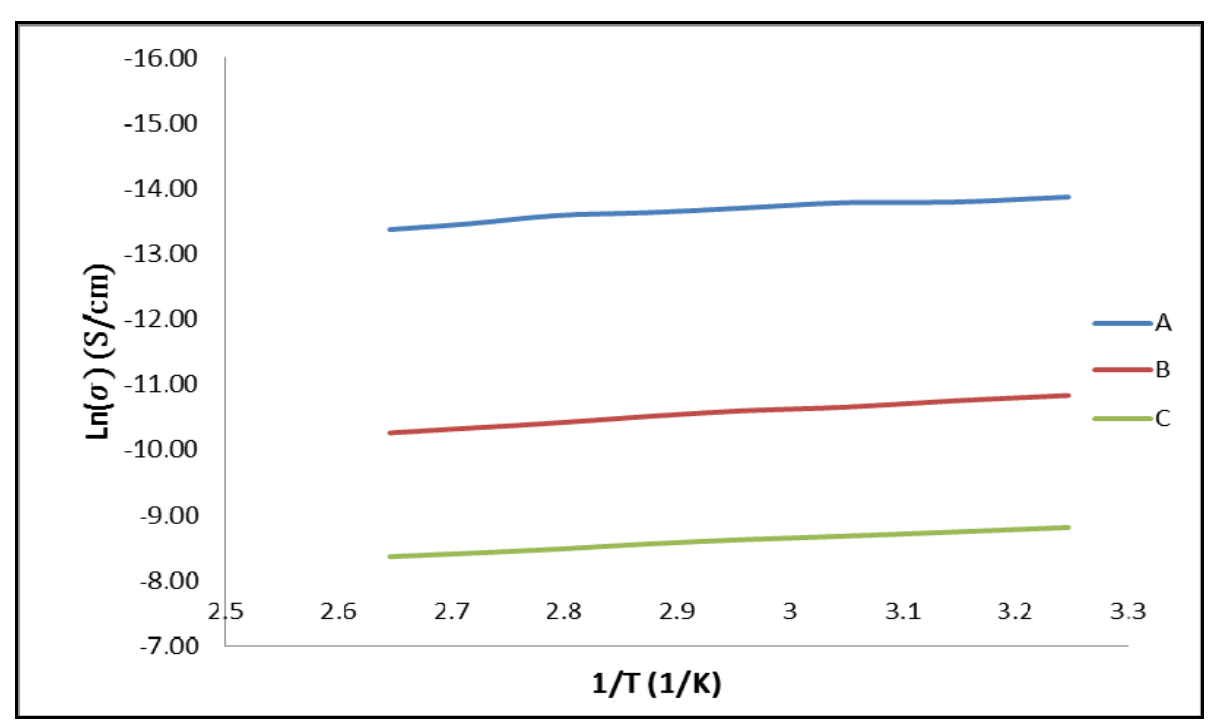

Fig. 6 Plot of Ln $\sigma$ versus 1/T for doped PU: (A) PU-20\%POT, (B) PU-30\%POT, (C) PU-10\%POT.

increasing amounts of the POT dopant and increased with increasing temperatures due to an increase in the efficiency of charge transfer, where the conductivity in the ratio of $20 \%$ doped started from $9.389 \mathrm{E}-07$ at $308 \mathrm{~K}$ to be $1.561 \mathrm{E}-06$ at $378 \mathrm{~K}$ and in the ratios of $30 \%$ and $50 \%$ doped started from 1.962E-05 and 
$1.48 \mathrm{E}-04$ at $308 \mathrm{~K}$ to be $3.519 \mathrm{E}-05$ and $2.336 \mathrm{E}-04$ at $378 \mathrm{k}$ respectively, in other way, the polymer behaves semiconductor material [20-22]. The increase in the conductivity due to increase in the charge carriers (Polarons and Bipolarons) which are leads to increase the current with increase the applied voltage in the electric circuit [23].

The activation energy of doped PU with different weight ratios of POT is calculated according to Arrhenius model [24] in which the conductivity $(\sigma)$ is given by the following:

$$
\begin{aligned}
& \sigma=\sigma_{0} \exp \left(-\mathrm{E}_{\mathrm{a}} / \mathrm{K}_{\mathrm{B}} \mathrm{T}\right) \\
& \ln \sigma=\left(-\mathrm{E}_{\mathrm{a}} / \mathrm{K}_{\mathrm{B}} \mathrm{T}\right)+\ln \sigma_{0}
\end{aligned}
$$

This equation has same form of straight line and then the plot of $\ln \sigma$ Vs $1 / \mathrm{T}$ (as shown in Fig. 6). The activation energy of doped PU by different weight ratios $(20 \%, 30 \%, 50 \%$ POT) was estimated to be $(0.069,0.0827,0.0649 \mathrm{eV})$ respectively. The decrease in activation energy of PU with increasing the amount of dopant (POT) is noted and attributed to the localize state presented.

\section{Conclusions}

The PU is prepared from diisosyanate (DTI) and polyethylene glycol (PEG) and then doped by different weight ratios of POT. Thin films of prepared polymers (PU, doped PU) have been prepared by spin coating method on different substrates for study. The Current-voltage (I-V) characteristic of (AL/polymers/AL) samples at different dopants and different temperatures showed ohmic behavior at all applied voltage.

\section{Acknowledgments}

The authors wish to express their appreciation to Sheffield Hallam University/Material and Engineering Research Institute/UK for supported us and provide all the capabilities to complete the research in their laboratories.

\section{References}

[1] Hepburn, C. 1982. "Polyurethane Elastomer." Applied
Science Publishers, London.

[2] Wang, J. and Ye, L. 2015. "Structure and Properties of Polyvinyl Alcohol/Polyurethane Blends." Composites: Part B 69: 389-96.

[3] Xia, H.-S. and Song, M. 2005. "Preparation and Characterization of Polyurethane-Carbon Nanotube Composites." Soft Matter 1: 386-94.

[4] Sen, R., Zhao, B., Perea, D., Itkis, M. E., Hu, H. and Love, J. et al. 2004. "Preparation of Single-Walled Carbon Nanotube Reinforced Polystyrene and Polyurethane Nanofibers and Membranes by Electrospinning." Nano Letters 4: 459-64.

[5] Lee, J., Park, E. J., Choi, J., Hong, J. and Shim, S. E. 2010. "Polyurethane/PEG-Modified MWCNT Composite Film for the Chemical Vapour Sensor Application." Synthetic Metals 160: 566-74.

[6] Chung, H. and Washburn, N. R. 2012. "Improved Lignin Polyurethane Properties with Lewis Acid Treatment." ACS Appl. Mater. Interfaces 4: 2840-6.

[7] Wang, W.-J., Chin, W.-K. and Wang, W.-J. 2002. "Synthesis and Structural Characterizations of [Chromophore]+-Saponite/Polyurethane

Nanocomposites." Journal of Polymer Science Part B: Polymer Physics 40: 1690-703.

[8] Pigott, K. A., Frye, B. F., Allen, K. R., Steingiser, S. S., Darr, W. C. and Saunders, J. H. et al. 1960. "Development of Cast Urethane Elastomers for Ultimate Properties." 5: 391-5.

[9] Sonnenschein, M. F., Lysenko, Z., Brune, D. A., Wendt, B. L. and Schrock, A. K. 2005. "Enhancing Polyurethane Properties via Soft Segment Crystallization.” Polymer 46: 10158-66.

[10] Kumar, A., Ali, V., Kumar, S. and Husain, M. 2011. "Studies on Conductivity and Optical Properties of Poly (O-Toluidine)-Ferrous Sulfate Composites." International Journal of Polymer Anal. Charact. 16: 298-306.

[11] Fakher Alfahed, R. K. and Ajeel, K. I. 2015. "Electrical Properties of Blend Polymers of Polyvinyl Alcohol/Poly (Otoluidine) ." IJSBAR 23: 173-82.

[12] Xia, H.-S. and Song, M. 2005. "Preparation and Characterization of Polyurethane-Carbon Nanotube Composites." Soft Matter 1: 386-94.

[13] Baig, U., Sanagi, M. M. and Khan, A. A. 2014. "Preparation of an Organic-Inorganic Polyurethane- $\mathrm{Al}_{2} \mathrm{O}_{3}$ Anion Exchange Fibrous Composite and its Application in the Development of a Membrane Electrode for the Determination of Chromium (VI) in Water", RSC Adv. 4:63831-63839.

[14] Jr., F. A., Dorielle Price, T. and Bhansali, S. 2010. "Optimization of Interdigitated Electrode (IDE) Arrays for Impedance Based Evaluation of Hs 578T Cancer 
Cells." Journal of Physics: Conference Series 224: 012134

[15] Oliveira, S., Rebelo, L. P. N. and Marrucho, I. M. 2015. "Influence of Different Inorganic Salts on the Iconicity and Thermophysical Properties of 1-Ethyl-3-Methy Limidazolium Acetate Ionic Liquid." J. Chem. Eng. Data 60: 781-9.

[16] Nath, B. C., Gogoi, B., Boruah, M., Sharma, S., Khannama, M. and Ahmed, G. A. et al. 2014. "High Performance polyvinyl Alcohol/Multi Walled Carbon Nanotube/Polyaniline Hydrogel (PVA/MWCNT/PAni) Based Dye Sensitized Solar Cells." Electrochimica Acta 146: 106-11.

[17] Al-Luaibi, H. F. H. 2010. "Preparation of Conducting Poly (o-Toluidine) and Study of its Electrical and Optical Properties for Application as a Solar Cell.” Ph. D thesis, University of Basrah.

[18] Ziadan, K. M., Hussein, H. F. and Ajeel, K. I. 2012. "Study of the Electrical Characteristics of Poly(o-Toluidine) and Application in Solar Cell." Energy Procedia 18: 157-64.
[19] Zuo, F., Angelopoulos, M., Macdiarmide, A. G. and Epstein, A. J. 1987. "Transport Studies of Protonated Emeraldine Polymer: A Granular Polymeric Metal System." Phys Rev B 36: 3475.

[20] Chougule, M. A., Pawar, S. G., Godse, P. R., Mulik, R. N., Sen, S. and Patil, V. B. 2011. "Synthesis and Characterization of Polypyrrole (PPy) Thin Films." Soft. Nanosci. Letter 1: 6-10.

[21] Jain, N., Patidar, D., Saxena, N. S. and Sharam, K. 2006. "Temperature Dependence of DC Conductivity in Polyaniline-Metal Halide Composites." Indian Journal of pure and Applied Physics 44: 767-70.

[22] Lei, X.-P. and Su, Z.-X. 2007. "Novel Conducting Polyaniline Copolymers of Aniline and N-Phenylglycine.” Material Letters 61: 1158-61.

[23] Leclerc, M., Aparno, G. D. and Zotti, G. 1993. "Structure- Property Relationships in Polyaniline Derivatives." Synth Met. 55: 1527-32.

[24] Abdulla, H. S. and Abbo, A. I. 2012. "Optical and Electrical Properties of Thin Films of Polyaniline and Polypyrrole.” Int. J. Electrochem. Sci. 7: 10666-78. 